Journal of Mechanical Engineering and Sciences (JMES)

ISSN (Print): 2289-4659; e-ISSN: 2231-8380; Volume 1, pp. 124-132, December 2011

(C) Universiti Malaysia Pahang, Pekan, Pahang, Malaysia

DOI: http://dx.doi.org/10.15282/jmes.1.2011.11.0011

\title{
EXPERIMENTAL ANALYSIS OF HEAT AND MASS TRANSFER IN A PACKED BED
}

\author{
K.V. Suryanarayana ${ }^{1}$, G. Srinivasa Rao ${ }^{2}$, D.M. Reddy $\operatorname{Prasad}^{3}$, K.V. Sharma ${ }^{4}$ and \\ P.K. Sarma ${ }^{1}$ \\ ${ }^{1}$ Department of Chemical Engineering, Sri Venkateswara Engineering College, \\ Suryapet 508213, India, E-mail: kagita_surya@yahoo.com \\ ${ }^{2}$ Department of Mechanical Engineering, Kakatiya Institute of Technology and Science, \\ Warangal 506015, India \\ ${ }^{3}$ Faculty of Chemical Engineering, Universiti Malaysia Pahang, 26300 Gambang, \\ Kuantan, Pahang, Malaysia \\ ${ }^{4}$ Faculty of Mechanical Engineering, Universiti Malaysia Pahang, Kuantan, Pahang \\ ${ }^{5}$ International Director, GITAM University, Visakhapatnam 530045, India
}

\begin{abstract}
Experiments have been conducted to study the effect of mass flow rate on heat and mass transfer coefficients in a packed bed. It has been observed that an increase in mass flow rate of water increases the heat and mass transfer coefficients by 1.7-1.9 and 3.2-3.8 times, respectively, at $55-95{ }^{\circ} \mathrm{C}$. The diffusion of oxygen from packed bed inlet water, obtained from experimental data, can be used to estimate the mass transfer coefficients. The theoretical equation available in literature is compared and satisfactory agreement has been observed. The increase in inlet water temperature decreases both the heat and mass transfer coefficients by $60 \%$ and $25 \%$, respectively, because of the reduced driving force. The increase in oxygen concentration in inlet water has no significant effect on either heat or mass transfer coefficients.
\end{abstract}

Keywords: Packed bed; condensation heat transfer coefficients; diffusion mass transfer coefficients; oxygen.

\section{INTRODUCTION}

Boiler feed water may contain significant amounts of dissolved oxygen, which causes pitting and iron deposition. Packed beds are used to remove these dissolved and corrosive gases from boiler makeup feed water. The makeup water and the condensate are heated in the packed bed to remove oxygen before entry into the boiler, because even small amounts of dissolved gas can cause significant corrosion (Satya Narayana, Ramireddy, \& Venkataramana, 2011; Syam Sundar, \& Sharma, 2011). The high temperature of boiler feed water, if left untreated, will increase further the corrosivity due to dissolved oxygen. In the experimental packed bed, the incoming water falls on the top of the bed. The length of the bed is $1.2 \mathrm{~m}$ and it is packed with $38-\mathrm{mm}$ nominal size pall rings made of nylon. The bed is engulfed with steam at a set pressure. Experiments are conducted with different flow rates, pressures, and temperatures of packed bed water.

Rabas, Inoue and Shimizu (1987) presented experimental data on mass transfer coefficients of a counter-flow pall-ring packed bed. The authors have taken the data from full-sized packed beds operating at desalination plants, and checked the mass transfer performance of the two-inch pall-ring packing and spray nozzle distribution 
system. The effects of antifoam and the stripping steam flow rate on the effluent oxygen concentration are not considered. Ferro, Ghiazza, Bosio and Costa (2002) observed that oxygen concentration decreases with an increase in temperature of seawater at the inlet of a packed bed. Costa, Ferro, Ghiazza and Bosio (2006) observed the performance of oxygen stripping of a packed bed when the steam flow rate is low. They concluded the maximum oxygen content in the outlet water to be 20-30 ppb, even in the absence of steam. Studies of heat and mass transfer with non-condensable gas, such as oxygen, being stripped from boiler feed water are quite limited. Hence, it is proposed to conduct experiments to estimate the heat and mass transfer coefficients from a packed bed for different mass flows rates and temperatures, and to assess its impact on oxygen stripping from the boiler feed water.

\section{FABRICATION OF THE EXPERIMENTAL SETUP}

The experimental setup consists of a 0.15-m diameter column and a 1.2-m long packed bed. A 200-liter feed water storage tank, a steam jacket on the deaerator water inlet pipe for regulating its temperature, and a pump for circulating water are other accessories. In the steam circuit, a pressure regulator and steam trap are connected to a buffer tank for removal of water droplets after steam expansion in the pressure regulator. A water bath of 25-liter capacity with a copper coil to regulate the temperature of the sample water to $0-40{ }^{\circ} \mathrm{C}$ is connected to a dissolved oxygen (DO) meter and a condenser for increasing the temperature of inlet water (Sharma, Suryanarayana, Sarma, Rahman, Noor, \& Kadirgama, 2010). A schematic diagram of the experimental setup is shown in Figure 1.

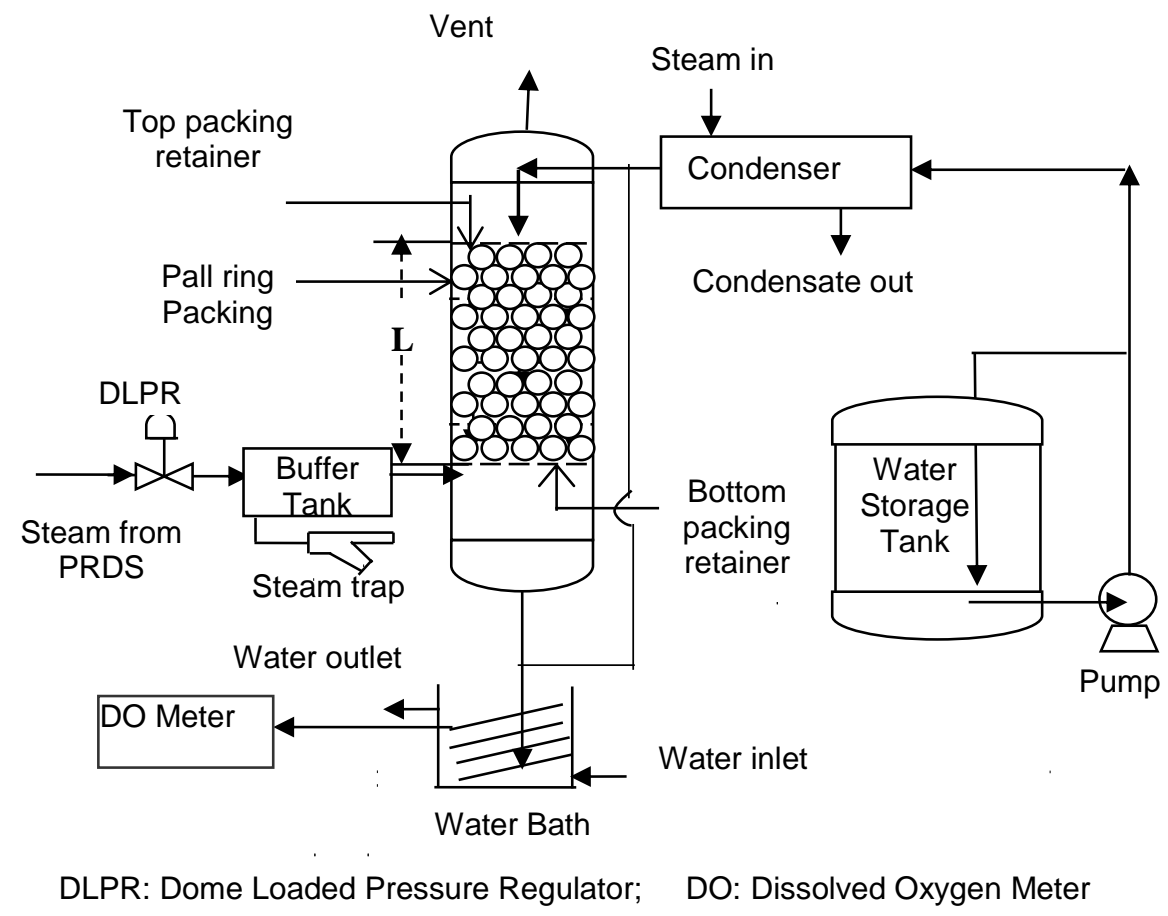

Figure 1. Schematic diagram of packed bed experimental setup 


\section{Estimation of Heat Transfer Coefficients}

The energy balance equation for the packed bed can be estimated from the relation

$$
Q_{E}=m C_{P L}\left(T_{o}-T_{i}\right)
$$

The heat transfer coefficient is estimated using $Q_{E}$ and the log-mean temperature difference as the driving force in the packed bed.

$$
h=\frac{Q_{E}}{A \Delta T_{L N}}
$$

\section{Estimation of Mass Transfer Coefficients}

The mass transfer is governed by the rate equation, which is given by

$$
J_{A}=k_{L, p} \Delta x_{L N}
$$

where $\Delta x_{L N}$ is the log-mean concentration difference and is expressed as

$$
\Delta x_{L N}=\frac{\left[\left(x_{i, P}-x_{i, P}^{*}\right)-\left(x_{0, P}-x_{o, P}^{*}\right)\right]}{\ln \left[\left(x_{i, P}-x_{i, P}^{*}\right) /\left(x_{o, P}-x_{o, P}^{*}\right)\right]}
$$

Rabas et al. (1987) have calculated the equilibrium concentration of oxygen in water at the inlet and outlet of a packed bed using the following equations:

$$
\begin{gathered}
x_{i, P}^{*}=\frac{\left(P_{D} / H_{C}\right)}{\left[\left(1+K_{e} M_{A} / M_{N 2}\right) M_{W} / M_{A}+\left(s+C_{p, i} \Delta T_{F} / H_{f g}\right) / x_{i}\right]} \\
x_{o, P}^{*}=\frac{y_{A} M_{A}}{P_{D} H_{C} M_{V}}
\end{gathered}
$$

Equations (4)-(6) are substituted in Eq. (3) to obtain an equation for mass transfer coefficient as

$$
k_{L, p}=\frac{V^{*}}{A_{C}} \frac{x_{i, P}-x_{o, P}}{\Delta x_{L N}}
$$

Another expression for the determination of the mass transfer coefficient has been given by Costa et al. (2006):

$$
k_{L, P}^{C}=\frac{N T U_{L M} L^{\prime}}{a A_{C} L}
$$

where $N T U_{L M}=\ln \frac{x_{i, P}}{x_{o, P}}$.

The mass transfer coefficients are evaluated using Eqs. (7) and (8), which are applicable to packed beds. 


\section{RESULTS AND DISCUSSION}

The increase in mass flow rate of packed bed water increases the heat transfer coefficients in the packed bed, as shown in Figure 2. The rate of increase is greater for inlet water temperature of $55^{\circ} \mathrm{C}$ compared with $95^{\circ} \mathrm{C}$ owing to the higher temperature potential between steam and water.

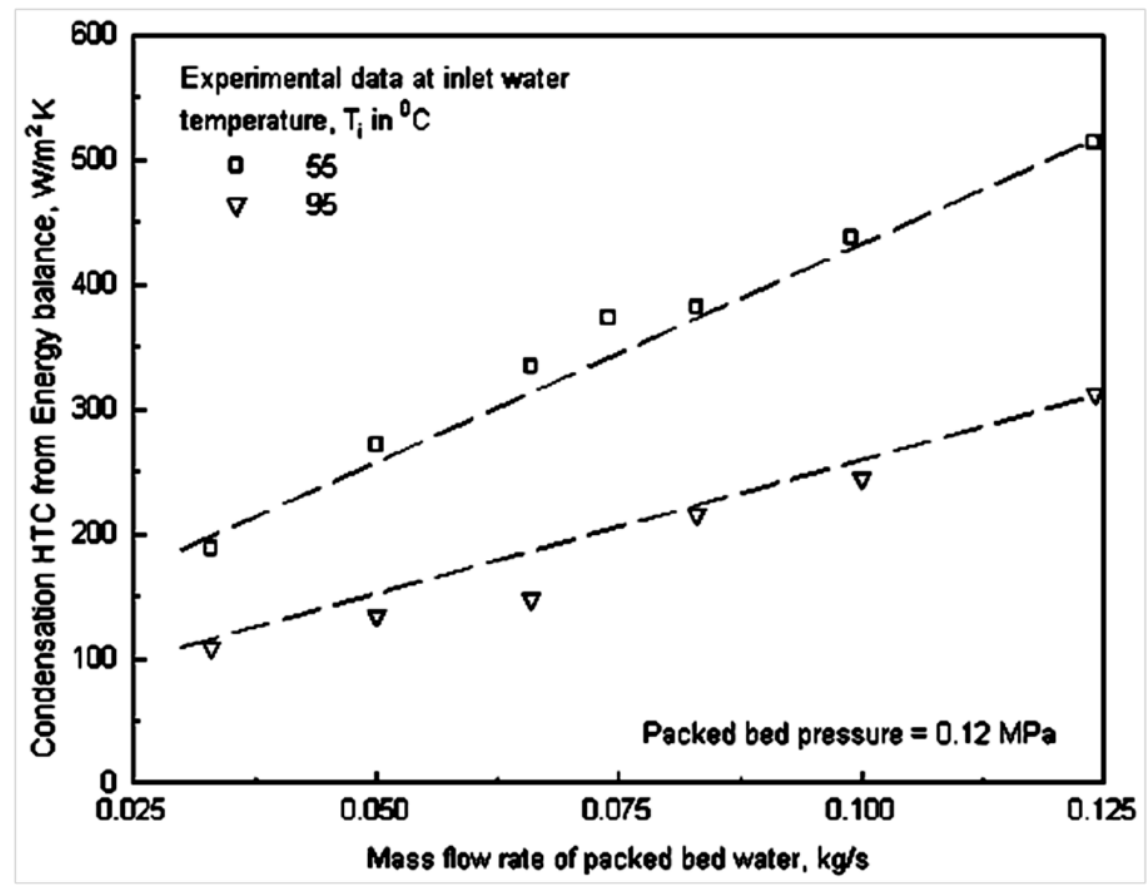

Figure 2. Effect of mass flow rate of packed bed water on condensation heat transfer coefficient for two different inlet water temperatures.

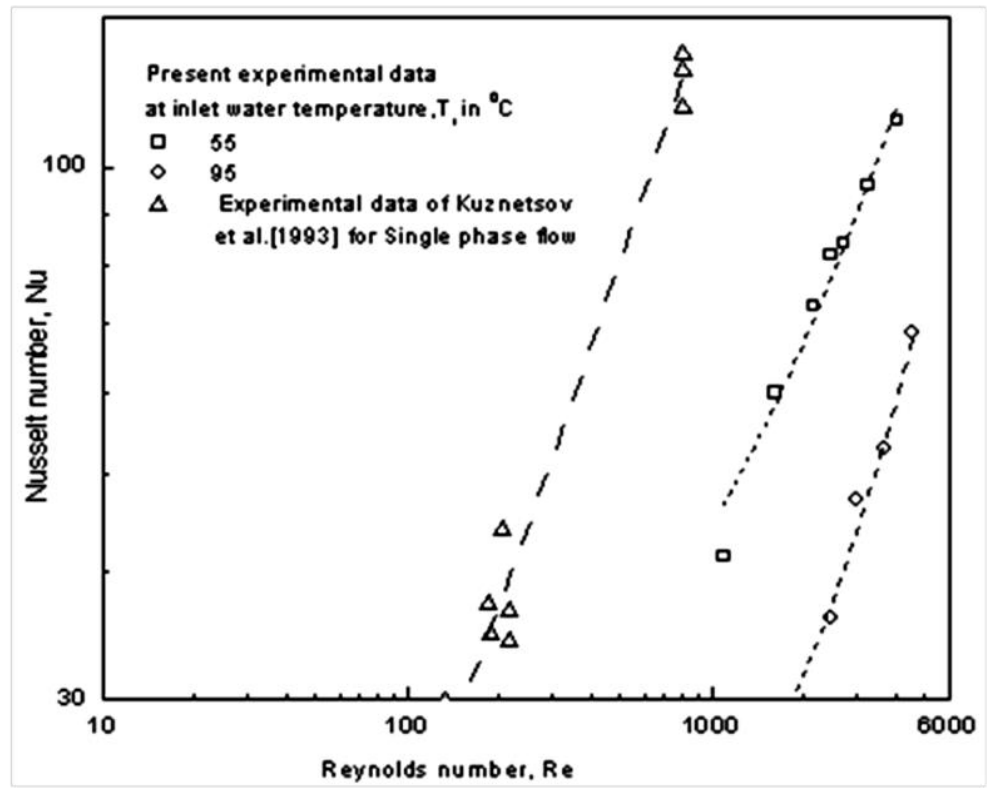

Figure 3. Comparison of present data with that from Kuznetsov et al. (1993) with porous systems and packing. 
The variation of the experimental Nusselt number with Reynolds number is shown in Figure 3, together with the data from Kuznetsov et al. (1993), which was obtained for upward gas-liquid flow in a tube filled with spheres. Experimental data with upward steam and downward water flow is not available in the literature. The trend of the present experimental data for different inlet water temperatures is satisfactory in comparison. The condensation heat transfer coefficient has no significant influence on inlet water oxygen concentration, as shown in Figure 4. The variation of condensation heat transfer coefficient with packed bed pressure is shown in Figure 5. The condensation heat transfer coefficient increases with an increase in packed bed pressure at lower temperatures, and remains constant at higher temperatures. This is due to the higher driving force between the steam and water.

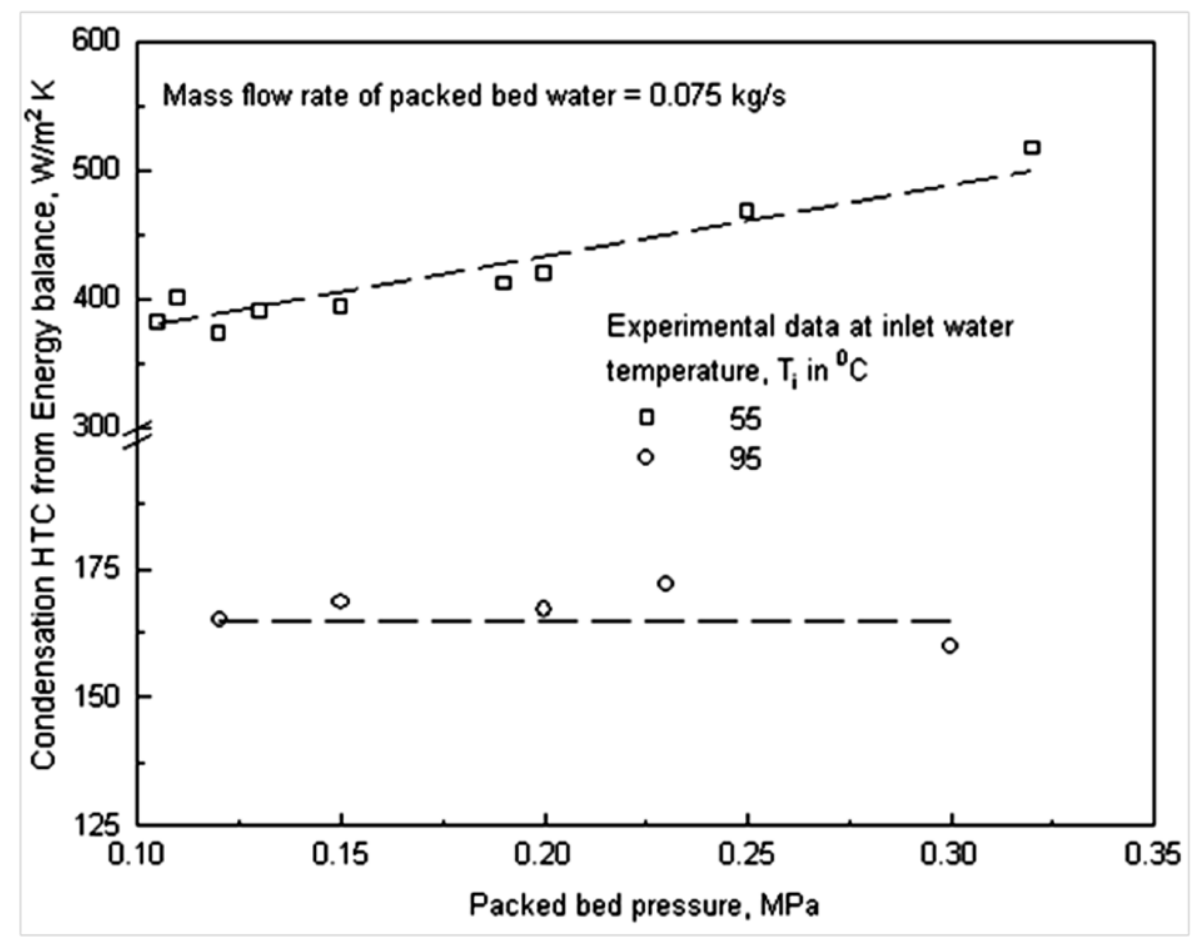

Figure 4. Effect of pressure of packed bed on condensation heat transfer coefficient for two different inlet water temperatures.

The increasing trends of mass transfer coefficient at different inlet water temperatures are shown in Figure 6. The increase in mass flow rate of water is similar to the increase in heat transfer coefficients, as can be seen from a comparison with Figure 2. The mass transfer coefficient has no significant influence with packed bed pressure, as shown in Figure 7. The mass transfer coefficient has no significant influence on oxygen concentration of inlet water, as shown in Figure 8. 


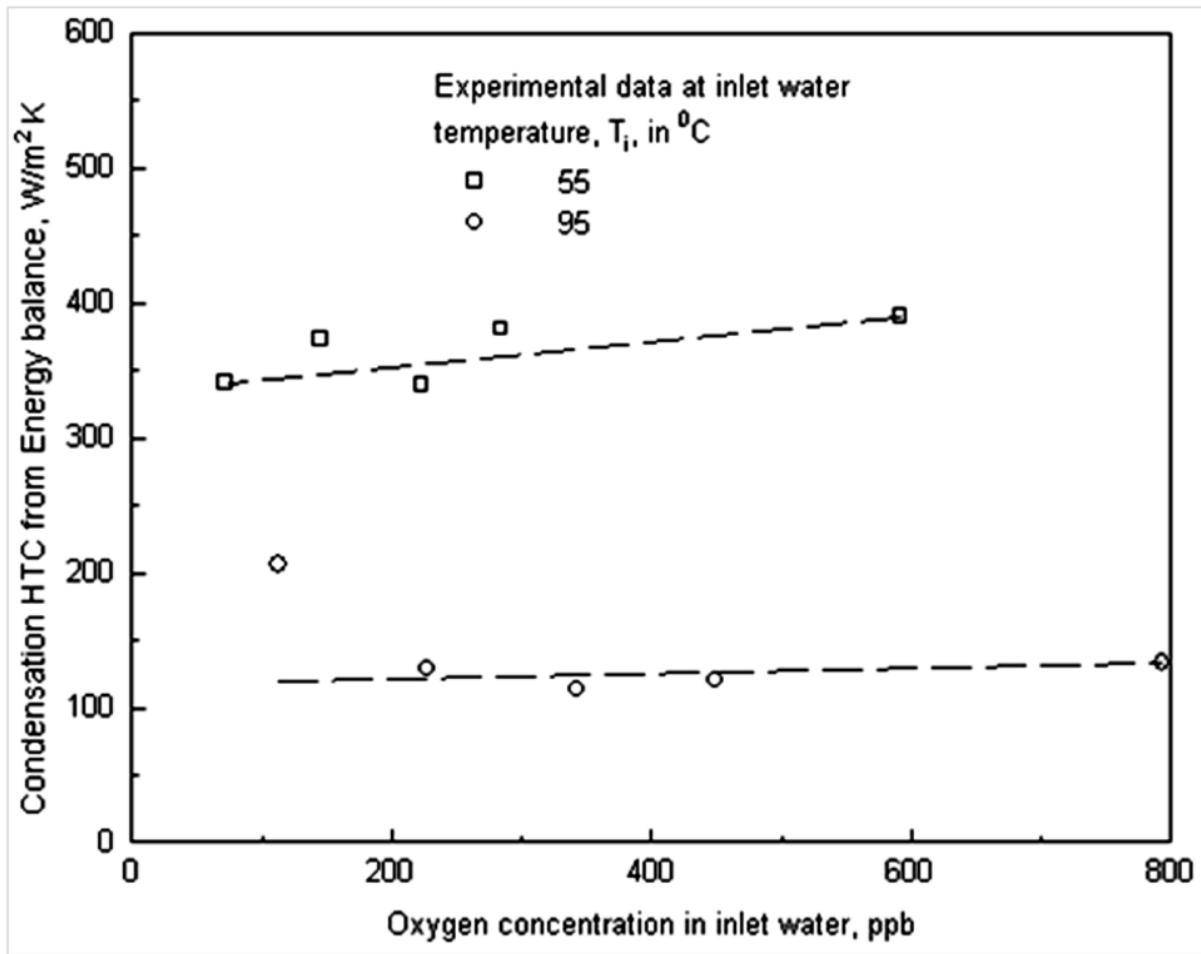

Figure 5. Effect of oxygen concentration in inlet water on condensation heat transfer coefficient for two different inlet water temperatures.

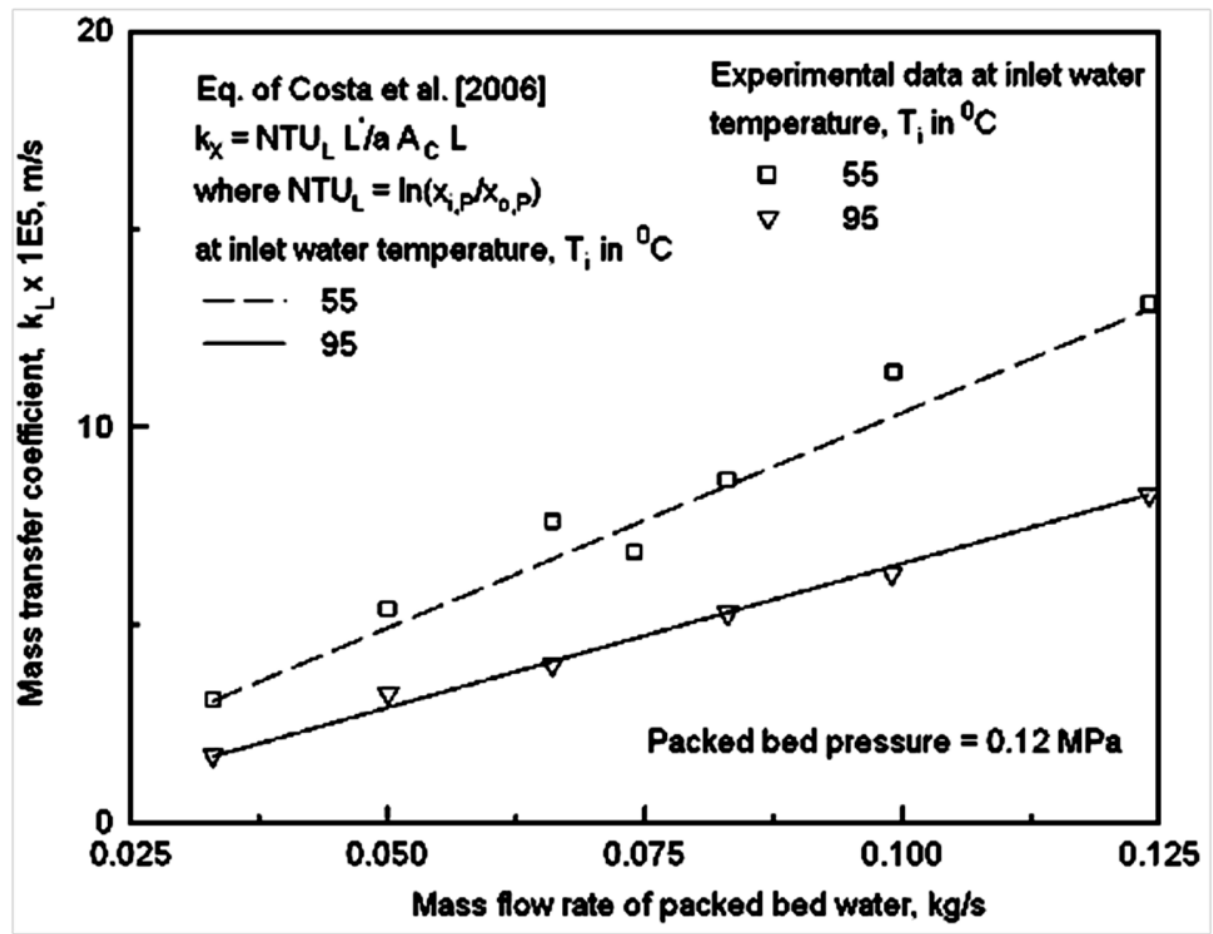

Figure 6. Effect of mass flow rate of packed bed water on mass transfer coefficient for two different inlet water temperatures. 


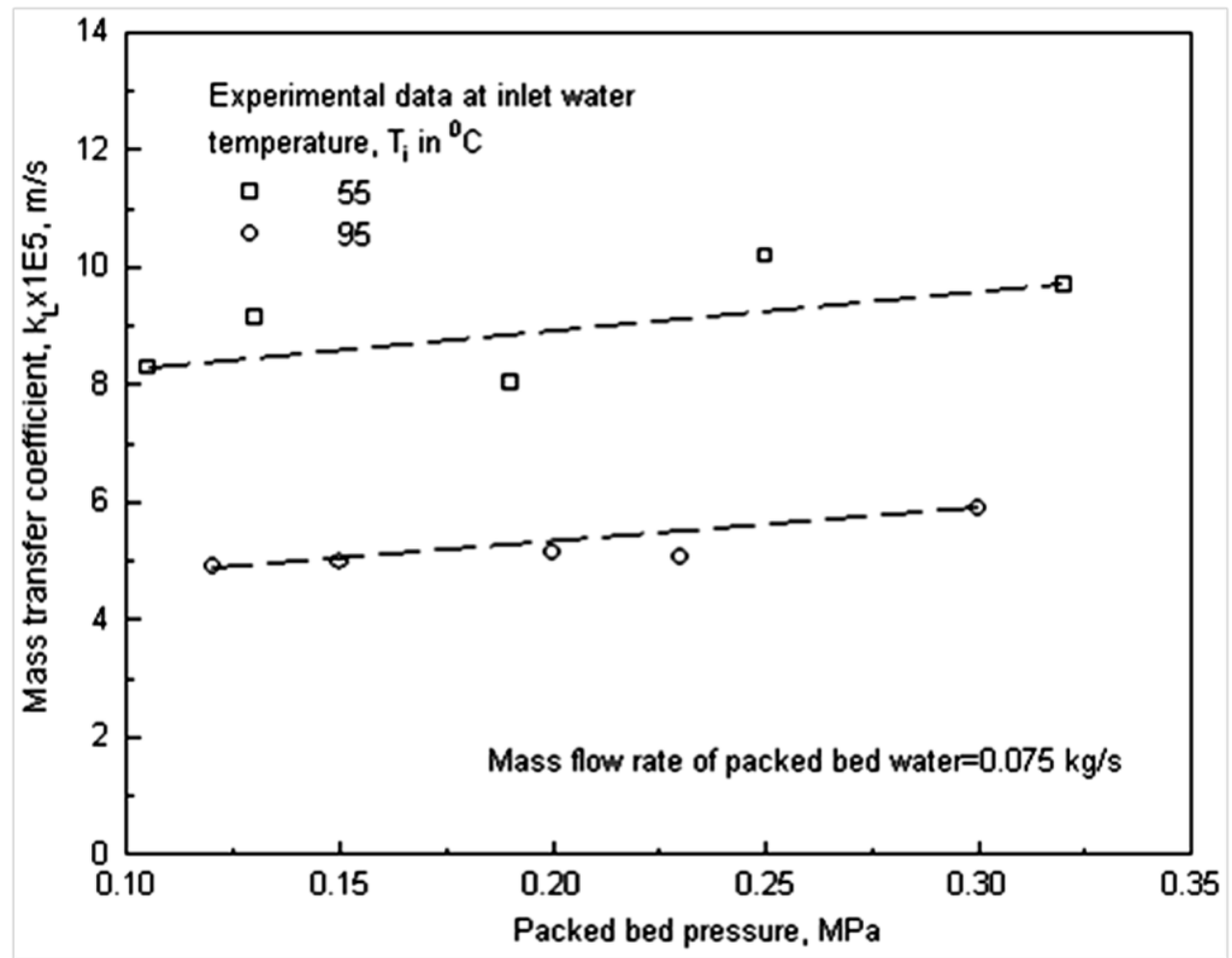

Figure 7. Effect of pressure of packed bed on mass transfer coefficient for two different inlet water temperatures.

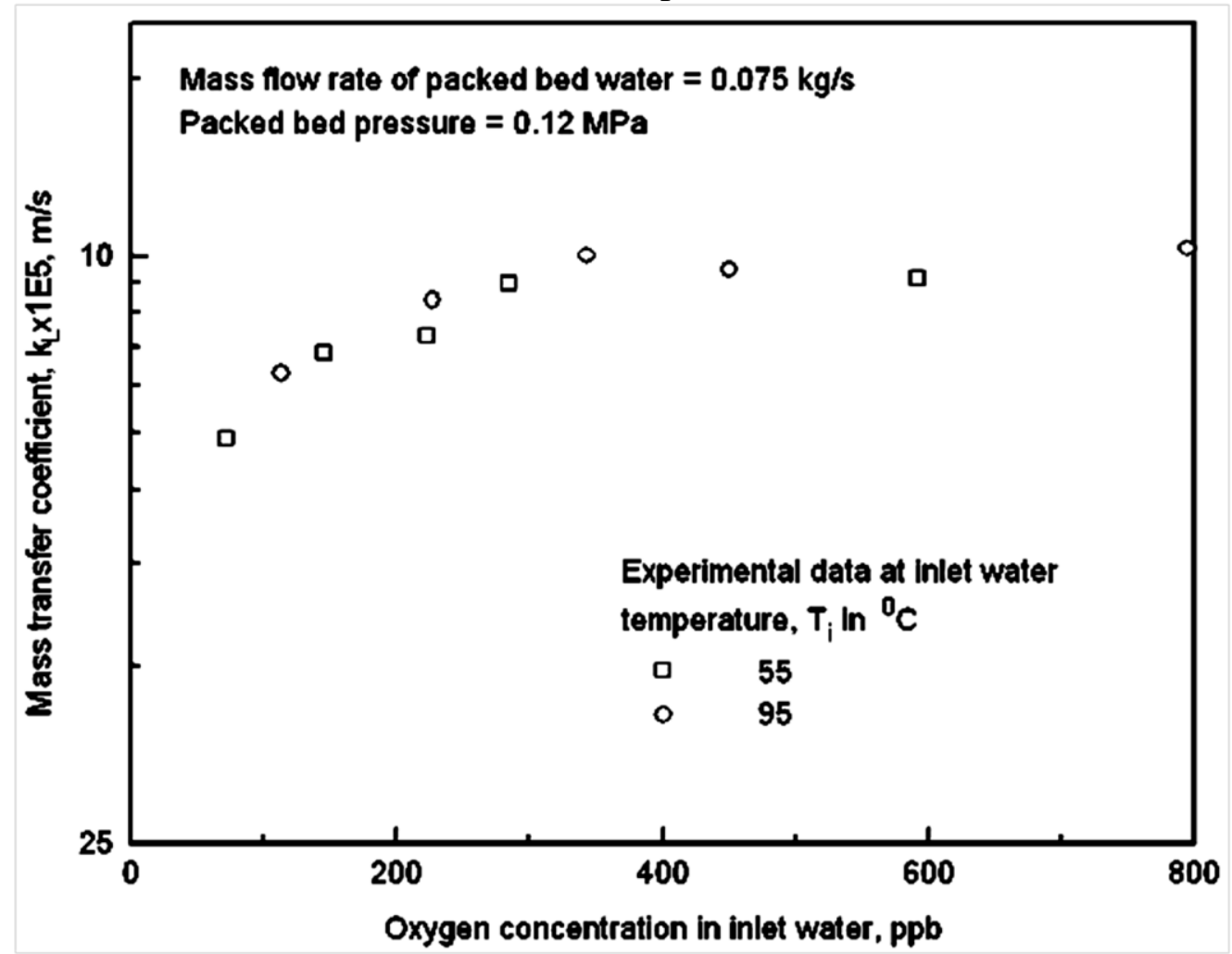

Figure 8. Effect of oxygen concentration in inlet water on mass transfer coefficient for two different inlet water temperatures. 


\section{CONCLUSIONS}

The following conclusions can be drawn from the present analysis:

a) The increase in mass flow rate of water in a packed bed increases the heat transfer coefficients. The values of heat transfer coefficient are in the range of $100-500 \mathrm{~W} / \mathrm{m}^{2} \mathrm{~K}$ for the experimental range tested.

b) The increase in flow rate of water in a packed bed increases the mass transfer coefficients.

c) The mass transfer coefficient in the packed bed estimated using the theoretical equation of Costa et al. (2006) is in good agreement with the present experimental values.

d) The increase in packed bed pressure increases both the heat and mass transfer coefficients by $25 \%$ and $12 \%$, respectively, at lower temperatures and remains constant at higher temperatures.

e) The increase in inlet water temperature decreases both the heat and mass transfer coefficients owing to a decrease in the driving force.

f) The increase in oxygen concentration of inlet water has no significant effect on the heat and mass transfer coefficients

\section{ACKNOWLEDGEMENTS}

Financial support by the Universiti Malaysia Pahang and DJR College of Engineering and Technology, Vijayawada, India, are gratefully acknowledged.

\section{REFERENCES}

Costa, P., Ferro, A., Ghiazza, E., \& Bosio, B. (2006). Seawater deaeration at very low steam flow rates in the stripping section. Desalination 201, 306-314.

Ferro, E., Ghiazza, E., Bosio, B., \& Costa, P. (2002). Modeling of flash and stripping phenomena in deaerators for seawater desalination. Desalination 142, 171-180.

Kuznetsov, V. V., \& Dimov, S. V. (1993). The influence of the geometrical parameters of a porous medium on two-phase filtration. $4^{\text {th }}$ Symp. Multiphase Transport in Porous Media: Prpc. ASME Winter Annual Meeting, Nov. 27-30, pp. 207-223

Rabas, T. J., Inoue, S., \& Shimizu, A. (1987). An update on the mass transfer of counter flow, packed deaerators containing pall-ring packing. Desalination, 66, 91-107.

Satya Narayana, P. V., Ramireddy, G., \& Venkataramana, S. (2011). Hall current effects on free-convection MHD flow past a porous plate. International Journal of Automotive and Mechanical Engineering, 3, 350-363.

Sharma, K. V., Suryanarayana, K. V., Sarma, P. K., Rahman, M. M., Noor, M. M., \& Kadirgama, K. (2010). Experimental investigations of oxygen stripping from feed water in a spray cum tray type deaerator. International Journal of Automotive and Mechanical Engineering, 1, 46-65.

Syam Sundar, L., \& Sharma, K.V. 2011. Laminar convective heat transfer and friction factor of $\mathrm{A} 12 \mathrm{O} 3$ nanofluid in circular tube fitted with twisted tape inserts. International Journal of Automotive and Mechanical Engineering, 3, 265-278. 


\section{NOMENCLATURE}

a packing area per unit volume, $\mathrm{m}^{2} / \mathrm{m}^{3}$

$A \quad$ surface area for heat transfer, $m^{2}$

$A_{C} \quad$ area of cross section for packed bed, $m^{2}$

$C_{P} \quad$ specific heat, $\mathrm{J} / \mathrm{kg} \mathrm{K}$

$D \quad$ diameter of the tank, $m$

$\Delta T_{F} \quad$ temperature drop or flashing at packing inlet, $0.3-0.6{ }^{\circ} \mathrm{C}$

$\Delta T_{L N} \quad$ log-mean temperature difference, $\left[\left(T_{S}-T_{i}\right)-\left(T_{S}-T_{o}\right)\right] / \ln \left[\left(T_{S}-T_{i}\right) /\left(T_{S}-T_{o}\right)\right]$

$h \quad$ heat transfer coefficient, $W / m^{2} K$

$H_{C} \quad$ Henry's law constant, $N / m^{2} / p p b$

$H_{f g} \quad$ latent heat of condensation, $\mathrm{J} / \mathrm{kg}$

$J_{A} \quad$ molar flux of component A, $\mathrm{kg}-\mathrm{mol} / \mathrm{m}^{2} \mathrm{~s}$

$k \quad$ thermal conductivity of water, $W / m K$

$K_{e} \quad$ ratio of oxygen to nitrogen mass at packing inlet $(\approx 1.75)$

$k_{L} \quad$ mass transfer coefficient, $\mathrm{m} / \mathrm{s}$

$L \quad$ length, $m$

$L^{\prime} \quad$ superficial mass velocity of flowing liquid, $\mathrm{kg} / \mathrm{m}^{2} \mathrm{~s}$

M molecular weight, $\mathrm{kg} / \mathrm{kg}-\mathrm{mol}$

$m$ mass flow rate of water, $\mathrm{kg} / \mathrm{s}$

$N T U_{L m}$ number of liquid phase transfer units for mass transfer

$\mathrm{Nu} \quad$ Nusselt number, $h D / k$

$Q \quad$ heat transfer, $W$

Re Reynolds number, $4 m / \pi D \mu$

$s \quad$ mass flow rate ratio of stripping steam to the inlet water

$T$ temperature, $K$

$\stackrel{*}{V} \quad$ volumetric flow rate of water into the deaerator, $\mathrm{m}^{3} / \mathrm{s}$

$x \quad$ mole fraction of $\mathrm{O}_{2}$ in water

$x^{*} \quad$ equilibrium mole fraction of $\mathrm{O}_{2}$ in water

$y \quad$ mole fraction of $\mathrm{O}_{2}$ in steam

$V \quad$ velocity of liquid, $\mathrm{m} / \mathrm{s}$

$\mu \quad$ viscosity of water, $\mathrm{kg} / \mathrm{ms}$

$A \quad$ oxygen or non-condensable gas

$A V$ average

$E \quad$ energy balance

$i$ inlet

$L \quad$ liquid

N2 nitrogen

$o$ outlet

$P \quad$ packed bed

$V \quad$ water vapor

$W \quad$ water 